\title{
Hemşirelerin Kanıta Dayalı Uygulamaya İlişkin Görüşleri
}

\author{
Opinions of Nurses in Relation to Evidence-Based Practice
}

\author{
Meryem YILMAZ ${ }^{1}$, Hesna GÜRLER²
}

İletişim/ Correspondence: Meryem YILMAZ Adres/ Address: Cumhuriyet Üniversitesi Sağlık Bilimler Fakültesi, Hemşirelik Bölümü, Cerrahi Hastalıklar Hemşireliği AD. Sivas, Tel: 03462191010 E-mail: yilmazmm01@hotmail.com

\begin{abstract}
$\ddot{O} Z$
Amaç: Bu çalışma iki kamu hastanesinde çalışan bir grup hemşirenin kanıta dayalı uygulamaya (KDU) ilişkin görüşleri, uygulama engelleri ve önerilerini belirlemek amacı ile tanımlayıcı olarak yapıldı.

Yöntem: Araştırmanın örneklemini bir üniversite ve bir devlet hastanesi olmak üzere iki kamu hastanesinde çallşan 371 hemşire oluşturdu. Araştırmada araştırmacılar tarafindan literatür taranarak iki bölümden oluşturulan anket formu kullanıldi. Anket formunun birinci bölümünde; hemşirelerin çalıştı̆̆ kurum, yaş, cinsiyet, eğitim düzeyi, çalışma yıl gibi demografik bilgileri içeren 6 soru, ikinci bölümde; hemşirelerin KDU ile ilişkili görüşleri, KDU engelleyen faktörler ve KDU yönelik önerilerini belirlemeye yönelik 18 olmak üzere toplam 24 soruya yer verildi. Verilerin değerlendirilmesinde sayı ve yüzdelik kullanildı.

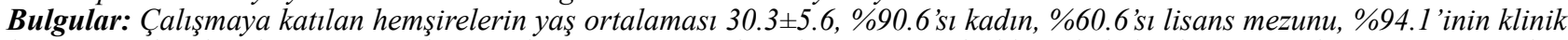
hemşiresi olarak çalıştığ ve ortalama çalışma süresi ortalamalarının 8.8 yıl olduğu belirlendi. Hemşirelerin KDU görüşleri kapsamında \%96.5'inin hemşirelik bakımının kanıta dayalı olması gerektiğini, \%49.1 'inin KDU "bakımın araştırmalardan elde edilmiş bir temele dayandırılması” şeklinde tanımladığ,$\% 75.5$ 'inin hasta bakımını eğitim sirasında aldıkları bilgiye göre uyguladıkları, \%97'sinin KDU'nın bakım kalitesini artırdığını ifade ettikleri saptand. Çalışmada hemşirelerin KDU engeli olarak $\% 85.7$ 'sinin eleman, zaman, fizik ortam ve malzeme yetersizliğini ifade ettiği ve \%37.5'inin hemşirelere KDU ile ilişkili hizmet içi ĕgitim verilmesi önerisinde bulunduğu belirlendi.

Sonuç: Bu çalışma sonucuna göre hemşirelerin KDU'ya olumlu bakmakla birlikte hasta bakımında araştırma sonuçlarını kullanma oranının çok düşük olması KDU'nın farkında olmadıklarını ancak hizmet içi eğitim verilerek bilgi ve farkındalıkların arttırılması, olanaklar ve kurum desteği să̆lanması durumunda kanıt temelli çalışabilecekleri söylenebilir.

Anahtar Kelimeler: Kanıt, kanıta-dayalı uygulama, kanıta dayalı uygulama için engeller, hemşirelik.
\end{abstract}

\section{ABSTRACT}

Aim: This study was carried out as descriptive to determine opinions, practice barriers and recommendations of a group of nurses working in two public nurses in relation to evidenced-based practice.

Method: The sample of the study included 371 nurses working in two public hospitals including an university hospital and a Public Hospital. The questionnaire form including two parts prepared according to literature by researchers was used in study. The questionnaire included a total of 24 questions containing 6 questions for demographic informations such as work institution, age, gender, level of education, working time of the nurses in the first part of the questionnaire and 18 questions for the opinions, barriers and recommendations of nurses in relation to evidenced-based practice. The number and percentage was used in the evaluation of the data.

Results: It was determined that average of age of nurses was 30.3 $55.6,90.6 \%$ were women, $60.6 \%$ had bachelor degree, $94.1 \%$ has been working as a clinical nurse, average working time was 8.8 years. In the context of opinions of nurses evidence-based practice, it was established that, 96.5\% of nurses stated nursing care should be evidence-based, $49.1 \%$ of nurses described evidence-based practice as "care have been based a basis obtained from researchs," 75.5\% applied patient care according to the information they received during training, , 97\% stated evidence-based practice enhanced the quality of care. In the study, it was identified that $85 \%$ of nurses stated lack of staff, time, physical environment and material were evidence-based practice barriers and $37.5 \%$ recommended that in-service training about evidence-based practice should be given.

Conclusion: In this study, it was determined that nurses'levels of knowledge and practice of evidence-based were insufficient. It was concluded that in-service training for nurses in relation to evidence-based practice should be given and institutional support should be provided.

Keywords: Evidence, evidence-based practice, barriers to evidence-based practice nursing.

${ }^{1}$ Doç. Dr. Cumhuriyet Üniversitesi Sağllk Bilimler Fakültesi, Hemşirelik Bölümü, Sivas/ TURKEY, ${ }^{2}$ Arş. Gör. Cumhuriyet Üniversitesi Sağglk Bilimler Fakültesi, Hemşirelik Bölümü, Sivas/ TURKEY.

Yazının gönderilme tarihi: 06.01.2016

Yazının basım için kabul tarihi: 02.01.2017

doi: 10.17672/fnhd.12049 


\section{GİRIŞ}

Kanıta dayalı uygulama (KDU), İngiliz hekimepidemiyolog Archie Cochrane'ın, 1970'li yılların başlarında sağlık bakım kararlarının bireysel görüş ya da deneyimlere göre değil, kanıta dayalı olması gerektiğine dikkat çekmesiyle başlayan interdisipliner bir klinik uygulama yaklaşımıdır (Adib-Hajbaghery 2009; Williamson, Almaskari, Lester ve Maguire 2015; Y1lmaz 2005). KDU amac1; bilginin yönetimi, maliyeti azaltma ve hasta bakımını en iyi düzeye getirmedir. Araştırma kanıtlarında KDU'nın güvenlik kültürü oluşturduğu, sağlık bakım maliyetini ve hastanede kalma uzunluğunu azalttığı, gereksiz ya da etkisiz uygulamaların ortadan kaldırılmasını sağladığı, hasta sonuçlarını iyileştirdiği ve bakım kalitesini yükselttiği gösterilmiştir (Melnyk ve Fineout-Overholt 2005; Melnyk, Fineout-Overholt, Gallagher-Ford ve Stillwell 2011; Melnyk, Gallagher-Ford, Long ve FineoutOverholt 2014). 1988 yilında yapılan 84 deneysel çalışmanın incelendiği bir meta analiz çalışmasında (Heater, Becker ve Olson 1988) araştırma temelli bakım alan hastaların sonuçları $\% 28$ oranında standart hemşirelik bakımı alan hastaların \%72'sinden daha iyi sonuç verdiği ancak, bakımın geleneksel uygulamaya gömülü kaldığı sonucuna varılmıştır. KDU farklı şekillerde tanımlanmıştır; kabul gören ve en yaygın kullanılan tanımı "bakımı etkileyecek klinik bir karar vermek için en iyi bilimsel kanıtı, klinik uzman ve hasta tercihlerini uygun olanakların bulunduğu bir çevrede kullanma süreci” olarak tanımlanmış olanıdır (Melnyk ve ark. 2011; Sackett, Rosenberg, Gray, Haynes ve Richardson 1996). Bu geniş bir tanımdır ve çeşitli bilgi türlerini kapsamaktadır: araştırma, klinik uzmanlık, bireysel hasta tercihleri ve değerleri ve uygulama olanakları/şartları. Aynı zamanda bu tanım her bir hasta için karar verirken var olan olanaklar/koşullar ve hasta tercihlerini dikkate alarak mevcut en iyi kanıtın bilinçli, açık ve akılcı kullanımının önemini göstermektedir. Melynk ve Fineout-Overholt (2005)'a göre KDU, karmaşık sağlık bakım sisteminde belirsizlikleri azaltmak ve sağlık bakım kalitesini arttırmak için önemli bir stratejidir. Bu strateji, klinik problemi belirlemeyi ve çözmeyi hedefleyen beş aşamadan oluşmaktadır: (1) yanıtlanabilecek soruları/ klinik problemi belirleme (2) literatür ve klinik rehberler sistematik araştırılarak en uygun bilgiyi toplama (3) kanıtı doğruluk, uygunluk, geçerlilik yönünden kritik değerlendirme (4) araştırma kanıtının klinik uzman, hasta değer ve tercihleri ile entegrasyonu (5) tedavi sonuçlarını değerlendirme.

Uluslararası düzeyde hemşirelikte KDU ve uygulamaya rehberlik edecek bilimsel kanıtı kullanmaya karşı güçlü bir istek (Sherriff, Wallis ve Chaboyer 2007) ve hemşirelik araştırmacıları tarafından hemşirelerin uygulamaya rehberlik için bilimsel kanıtı kullanmaya yönelik olumlu tutumları olmasına rağmen (AdibHajbaghery 2009; Majid ve ark. 2011), sunulan hemşirelik uygulamasında kanıt kullanımının yeterli olmadığı (Adib-Hajbaghery 2009), hemşirelerin KDU'nın yararı hakkındaki inançlarının yüksek, bilgilerinin düşük olduğu (Melnyk ve ark. 2004), hemşirelerin belirsizlik ile karşı karşıya geldiğinde başvurdukları bilginin en önemli iki kaynağının makale ve kitap gibi formal bilgiler yerine arkadaş gibi sosyal etkileşimler ve bireysel deneyimler olduğu (Estabrooks, Chong, Brigidear ve Profetto-McGrath 2005; Gerrish, Ashworth, Lacey ve Bailey 2008) hemşirelerin klinik karar vermeleri gereken durumlarda kanıta dayalı kaynaklar yerine formal olmayan kaynaklara güvenme eğiliminde oldukları gösterilmiştir (McCaughan, Thompson, Cullum, Sheldon ve Thompson 2002). Hemşirelerin KDU'ya yönelik çalışmama nedeni olarak klinisyenlerin KDU konusunda bilgi ve beceri eksikliği, KDU zamanlı/süreli algılamaları, KDU'nın ağır/ külfetli olduğu, hasta için çok az yarar sağladığına ilişkin inançları gibi bireysel ve KDU desteklemeyen örgütsel kültür gibi kurumsal engeller bulunduğu rapor edilmiştir (Beckette ve ark. 2011; Brown, Wickline, Ecoff ve Glaser 2009; Estabrooks, Floyd, Scott-Findlay, O'Leary ve Gushta 2003; Melnyk ve ark. 2004). Bu engellerin yanı sıra KDU ile ilişkili en yaygın eleştiri, KDU'da en büyük çabanın girişimlerin klinikte uygulanmasından ziyade ilk amaç üzerine yani en etkili girişimin/ kanıtın oluşturulması üzerine odaklanılmasıdır. Örneğin; 1980'lerde kanıta dayalı tıp olarak ortaya çıkan 
biyomedikal merkezli kaygının, randomize kontrollü çalışmalardan (RKÇ) elde edilmiş kanıtın sentezlenememesi ve rutin klinik uygulama içine dahil etme yolunun bulunamaması olarak bildirilmektedir (Sackett ve ark. 1996). Dünya'da hemşirelerin KDU'nın bakım kalitesi üzerine yararları, engelleri ve farkındalıklarına yönelik pek çok çalışma bulunurken, Türkiye'de çoğunlukla hemşirelerin araştırma engelleri üzerine yapılmış çalışmalar bulunmaktadır. Bu bağlamda bu çalışmada hemşirelerin KDU ile ilişkili görüşleri, KDU'y1 engelleyen faktörler ve KDU'ya yönelik önerilerinin belirlenmesi hedeflendi. Bu çalışma, Sivas ilinde bulunan bir üniversite hastanesi ve devlet hastanesinde çalışan hemşirelerin KDU ile ilişkili görüşleri, KDU engelleyen faktörler ve KDU yönelik önerilerini belirlemek amacıyla yapıldı.

\section{YÖNTEM}

\section{Araştırmanın Tipi}

$\mathrm{Bu}$ çalışma, tanımlayıcı tipte planlandı ve uygulandı.

\section{Araştırmanın Evreni ve Örneklemi}

Araştırmanın evrenini 613 hemşire oluşturdu. Araştırmanın uygulandığ tarihlerde izinli, raporlu olma ve araştırmaya katılmayı kabul etmeme nedenleri ile araştırmanın örneklemini üniversite hastanesinden 223 ve devlet hastanesinden 148 olmak üzere toplam 371 hemşire oluşturdu. Çalışmaya katılacak hemşireler olasılıksız örnekleme yöntemi ile seçildi. Hemşirelerin çalışmaya katılım oranı \%61 idi. Araştırmanın yapıldığ1 üniversite hastanesinde 2012 yılında başhemşirelik, başhekimlik ve başmüdürlük işbirliği ile kurum düzeyinde Araştırma ve Geliştirme (ARGE) birimi kurulmuştur. Bu birimde araştırma yapmak isteyen hemşirelere danışmanlık ve eğitim yapan aynı zamanda kendisi de araştırmaların içinde yer alan yüksek lisans mezunu bir hemşire bulunmaktadır. Hastane yönetimi araştırma yapmak isteyen hemşireleri maddi ve manevi olarak desteklemektedir. Ayrıca hemşireler tarafından belirlenmiş konularda hizmet-içi eğitim programları yapılmaktadır. Devlet hastanesinde böyle bir birim bulunmamakla birlikte hemşirelerin bilimsel toplantılara katılımları desteklenmekte ve gereksinim duyulan konularda hizmet içi eğitim verilmektedir.

\section{Veri Toplama Araçları ve Verilerin Toplanması}

Araştırmada araştırmacılar tarafından literatür taranarak (Berland, Gundersen ve Bentsen 2012; Melnyk ve ark. 2004; Pravikoff, Tanner ve Pierce 2005; Sackett ve ark. 1996) oluşturulmuş anket formu kullanıldı. Anket formu iki bölümden oluşturuldu. Birinci bölüm; hemşirelerin yaş, cinsiyet, eğitim düzeyi, çalışma yılı, çalıştığı kurum ve çalıştığı görev ile ilişkili verileri içeren 6 adet sorudan oluşturuldu. İkinci bölüm; hemşirelerin KDU ile ilişkili görüşleri kapsamında, hemşirelik bakımı kanıta dayalı olmalı mıdır, KDU bakım kalitesini artırır mı, KDU için bakımının araştırma temeline dayandırılması gerekir mi, hemşirelikte araştırma sonuçlarına kolaylıkla ulaşabiliyor musunuz, ulaştığ1nız araştırma sonucunu klinikte kullanıyor musunuz, ulaştığınız araştırma sonucunu ekip üyeleri ile paylaşır mısınız, KDU için şartlar ve çevre önemli mi, yaptığınız bakımın hasta üzerindeki etkisini biliyor musunuz, yaptığınız hasta bakımı bir araştırma kanıtına dayalı m1, hasta bakımını kanıta dayalı yapabileceğinize inanıyor musunuz, KDU için eğitime gereksiniminiz var mı, çalıştığınız kurum KDU için uygun mu, KDU için kurumsal destek önemli mi, çalıştığınız kurumda KDU için kurumsal destek yeterli mi, hasta bakımında ve yaşanan sorunlarda rehber alınan bilgi kaynakları ile ilişkili 15 adet kapalı uçlu, yönlendirme ve sınır getirmeden cevap verme imkanı sağlamak için KDU tanımı, KDU için engeller ve klinik ortamda KDU yönelik çalışılabilmeyi sağlayan önerileri içeren 3 adet açı uçlu soru olmak üzere toplam 24 adet sorudan oluşturuldu. Açık uçlu sorular iki uzman görüşü alınarak gruplandırıldı. Hemşirelerin KDU tanımı ise, Melnyk ve ark. (2011) tarafından yapılmış "bakımı etkileyecek klinik bir karar vermek için en iyi bilimsel kanıtı, klinik uzman ve hasta tercihlerini uygun olanakların bulunduğu bir çevrede kullanma süreci” tanımına göre değerlendirilerek gruplandırıldı. Bu bağlamda yalnızca araştırmalardan elde edilmiş temele dayandırılması şeklindeki tanım eksik olarak değerlendirildi. Bu çalışma verilerinin tamamı hemşirelerin ifadelerinden elde edilmiştir. 
Anket formu çalışmaya katılmayı kabul eden hemşirelere araştırmacılar tarafından yüz yüze görüşme yöntemi ile yaklaşık 15-20 dakikada kliniğin hemşire odasinda uygulandi.

\section{Araştırmanın Etik Yönü}

Veri toplama işlemine başlamadan önce çalışmanın yapılacağı kurumların yönetiminden yazılı izin alınd. Araştırmada "Helsinki İlkeler Deklarasyonu" ilkelerine uyuldu. Anket formu uygulanmadan önce hemşirelere araştırmanın amacı, araştırmadan beklenen yararlar, araştırmaya katılıp katılmama kararının kendilerine ait olduğu, anketlerin üzerine isim yazmamaları, elde edilen bilgilerin çalışma dışında kullanılmayacağı, kişisel bilgilerinin gizliliğinin korunacağı, herhangi bir zamanda katılım olurunu geri çekme hakkına sahip olduğu ile ilişkili bilgi verildi. Sözlü izinleri alındı ve daha sonra anket formu uygulandı.

\section{Verilerin Değerlendirilmesi}

$\mathrm{Bu}$ çalışmadan elde edilen veriler sosyal bilimler için paket programı (SPSS Inc., Chicago, IL, USA) SPSS 16.0 kullanılarak analiz edildi. Verilerin analizinde sayı ve yüzde kullanıldı.

\section{Araştırmanın Sınırlılıkları}

$\mathrm{Bu}$ çalışmanın kesitsel tanımlayıcı tipte ve soruların çoğunluğunun kapalı uçlu olması, verilerin hemşirelerin ifadelerine dayalı olması sınırlılığıdır. Bu nedenle çalışmanın sonuçları yalnızca çalışma grubuna genellenebilir. Çalışmanın bu sınırlılıklarına rağmen elde edilen bulgular hemşirelikte KDU'ya yönelik yapılacak araştırma ve eğitim programlarının düzenlenmesi konusuna katkı sağlayabilir.

\section{BULGULAR}

Sunulan çalışmaya katılan hemşirelerin yaş ortalamas1 30.3 \pm 5.6 , \%90.6's1 kadın ve \%60.6's1 lisans, $\% 23.7$ ön lisans, \%5.9 yüksek lisans, \%9.7 lise mezunu, \%94.1'inin klinik hemşiresi, \%5.4'ünün sorumlu hemşire ve $\% 0.5$ 'inin başhemşire olarak görev yapt1ğ1 ve ortalama çalışma süresinin $8.8 \pm 6.8$ olduğu belirlendi. Hemşirelerin KDU tanımları incelendiğinde \%49.1'inin "bakımın araştırmalardan elde edilmiş bir temele dayandırılmış olması" şeklinde tanımladığı ve \%25.9'unun KDU tanımlamadığı görüldü (Tablo 1).

Tablo 1. Hemşirelerin Kanıta Dayalı Uygulama ile İlişkili Tanımları

\begin{tabular}{|l|c|c|}
\hline Hemşirelerin KDU Tanımı $(\mathbf{n}=\mathbf{3 7 1})$ & $\mathbf{n}$ & $\mathbf{\%}$ \\
\hline $\begin{array}{l}\text { KDU, bakımın araştırmalardan elde } \\
\text { edilmiş bir temele dayandırılmasıdır }\end{array}$ & 182 & 49.1 \\
\hline $\begin{array}{l}\text { KDU, hemşirelik uygulamalarının kayıt } \\
\text { edilmesidir }\end{array}$ & 65 & 17.5 \\
\hline $\begin{array}{l}\text { KDU, neden sonuç ilişkisi kurularak } \\
\text { yapılan uygulamalardır }\end{array}$ & 20 & 5.4 \\
\hline KDU, hekim istemleridir & 5 & 1.3 \\
\hline $\begin{array}{l}\text { KDU, hastalık belirtisine göre tedavi } \\
\text { yapılmasıdır }\end{array}$ & 2 & 0.5 \\
\hline $\begin{array}{l}\text { KDU, yasalara uygun yapılan } \\
\text { uygulamalardır }\end{array}$ & 1 & 0.3 \\
\hline Cevapsız & 96 & 25.9 \\
\hline
\end{tabular}

Hemşirelerin \% 75.5'inin hasta bakımını eğitim sırasında aldıkları bilgiye göre \%26.1'inin ise kişisel deneyimlere göre yaptığı ve yalnızca \%4.04'ünün araştırma sonuçlarını kullandığı belirlendi (Tablo 2).

Tablo 2. Hemşirelerin Hasta Bakımında Kullandıkları Bilgi Kaynakları

\begin{tabular}{|l|c|c|}
\hline Kullanılan Bilgi Kaynakları* & n & \% \\
\hline Eğitim sırasında alınan bilgiler & 280 & 75.5 \\
\hline Kişisel deneyimler & 96 & 26.1 \\
\hline Sorumlu/başhemşireliğin beklentisi & 76 & 20.4 \\
\hline Hekim istemleri & 75 & 20.2 \\
\hline Klinik rutinler & 59 & 16.0 \\
\hline Araştırma sonuçları & 15 & 4.04 \\
\hline Bakım protokolleri & 7 & 1.9 \\
\hline
\end{tabular}

*Birden fazla seçenek işaretlenmiştir.

Hemşirelerin KDU'ya ilişkin görüşleri kapsamında; \%96.5'inin hemşirelik bakımının kanıta dayalı olmas1 gerektiğini, \%97'sinin KDU'nın bakım kalitesini artırdığını, \%97.8'inin KDU için bakımın araştırma temeline dayandırılması gerektiğini, \%48.5'inin araştırma sonuçlarına kolaylıkla ulaşamadığ araştırma sonuçlarını hasta bakımında kullandığını, 
Tablo 3. Hemşirelerin Kanıta Dayalı Uygulamaya İlişkin Görüşleri

\begin{tabular}{|c|c|c|c|c|}
\hline \multirow{2}{*}{ Görüşler } & \multicolumn{2}{|c|}{ Evet } & \multicolumn{2}{|c|}{ Hayır } \\
\hline & $\mathbf{n}$ & $\%$ & $\mathbf{n}$ & $\%$ \\
\hline Hemşirelik bakımı kanıta dayalı olmalı mıdır? & 358 & 96.5 & 13 & 3.5 \\
\hline Kanıta dayalı uygulama bakım kalitesini artırır mı? & 360 & 97.0 & 11 & 3.0 \\
\hline KDU için bakımının araştırma temeline dayandırılması gerekir mi? & 363 & 97.8 & 8 & 2.2 \\
\hline Hemşirelikte araştırma sonuçlarına kolaylıkla ulaşabiliyor musunuz? & 189 & 50.9 & 182 & 49.1 \\
\hline Ulaştığınız araştırma sonucunu klinikte kullanıyor musunuz?(n:189) & 178 & 94.2 & 11 & 5.8 \\
\hline Ulaştığınız araştırma sonucunu ekip üyeleri ile paylaşır mısınız?(n:189) & 188 & 99.5 & 1 & 0.5 \\
\hline KDU için şartlar ve çevre önemli mi? & 360 & 97.0 & 11 & 3.0 \\
\hline Yaptığınız bakımın hasta üzerindeki etkisini biliyor musunuz? & 363 & 97.8 & 8 & 2.2 \\
\hline Bakımla ilişkili sorularınızı tartışabileceğiniz birim var mı? & 295 & 79.5 & 76 & 20.5 \\
\hline Yaptığınız hasta bakımı bir araştırma kanıtına dayalı mı? & 319 & 86.0 & 52 & 14.0 \\
\hline Bakımınızı kanıta dayalı yapabileceğinize inanıyor musunuz? & 318 & 85.7 & 53 & 14.3 \\
\hline KDU için eğitime gereksiniminiz var mı? & 343 & 92.5 & 28 & 7.5 \\
\hline Çalıştığınız kurum KDU için uygun mu? & 202 & 54.4 & 169 & 45.6 \\
\hline KDU için kurumsal destek önemli mi? & 360 & 97.0 & 11 & 3.0 \\
\hline Çalıştığınız kurumda KDU için kurumsal destek yeterli mi? & 202 & 54.4 & 169 & 45.6 \\
\hline \multicolumn{5}{|l|}{ KDU engelleri $(n=41) *$} \\
\hline Eleman, zaman, fiziki ortam ve malzeme yetersizliği & 35 & 85.7 & & \\
\hline Hekim istemlerine yönelik ve iş merkezli çalışma & 8 & 26.6 & & \\
\hline Araştırma sonuçlarına ulaşamama & 5 & 16.7 & & \\
\hline
\end{tabular}

*Birden fazla seçenek işaretlenmiştir.

Tablo 4. Hemşirelerin Kanıta Dayalı Uygulamaya Yönelik Önerileri

\begin{tabular}{|l|c|c|}
\hline Öneriler $(\mathbf{n}=\mathbf{4 0}) *$ & $\mathbf{n}$ & $\mathbf{\%}$ \\
\hline $\begin{array}{l}\text { Hemşirelere KDU ile ilgili hizmet içi eğitim } \\
\text { verilmesi }\end{array}$ & 15 & 37.5 \\
\hline $\begin{array}{l}\text { Yapılan araştırma sonuçları hakkında sağlık } \\
\text { personelini bilgilendirme }\end{array}$ & 10 & 25.0 \\
\hline $\begin{array}{l}\text { Yönetimin değişim ve yeniliğe açık ve } \\
\text { destekleyici olması }\end{array}$ & 9 & 22.5 \\
\hline Araştırma sonuçlarına kolayca ulaşabilme & 6 & 15.0 \\
\hline Ortak bakım protokollerinin oluşturulması & 4 & 10.0 \\
\hline Güncel araştırmaların takip edilmesi & 4 & 10.0 \\
\hline Daha sağlıklı çalışma alanları oluşturulması & 4 & 10.0 \\
\hline Daha fazla araştırma yapma & 4 & 10.0 \\
\hline KDU takip edecek bir ekip oluşturulması & 3 & 7.5 \\
\hline İnternete ulaşma olanağının sağlanması & 2 & 5.0 \\
\hline Eleman ve malzemelerin temin edilmesi & 1 & 2.5 \\
\hline
\end{tabular}

*Birden fazla seçenek işaretlenmiştir. \%97.8'inin yapılan bakımın hasta üzerindeki etkisini bildiğini, \%92.5'inin KDU için eğitime ihtiyacı olduğunu, \%45.6'sının çalıştıkları kurumun KDU için uygun olmadığını, \%85.7'sinin çalıştıkları kurumda eleman, fiziki ortam ve malzeme yetersizliğinin KDU için engeller olduğunu ifade ettikleri saptandı (Tablo 3).

Hemşirelerin KDU için; \%37.5'inin kurumun hizmet içi eğitim vermesini, \%25'i yapılan araştırmaların sonuçları hakkında bilgilendirilmeyi ve \%22.5'i yönetimin değişim ve yeniliğe açık ve destekleyici olmasını önerdikleri görüldü (Tablo 4).

\section{TARTIŞMA}

KDU, sağlık bakım kalitesini arttırmak için ortaya çıkmış bir problem çözme yaklaşımı (Beyea ve Slattery 2013; Melnyk ve ark. 2011) olup, KDU'nın hemşirelerin kişisel ve profesyonel gelişiminin artmasına da 
katk1 verebilecek anahtar bir strateji olduğuna inanılmaktadır. Sunulan çalışmada hemşirelerin tamamına yakını hemşirelik bakımının kanıta dayalı olmasını ve KDU'nın bakım kalitesini arttıracağını onayladıkları belirlendi. Bir çalışmada (Melynk ve ark. 2004) hemşirelerin KDU'nın bakım kalitesini arttırdığına yönelik inançlarının yüksek, bilgilerinin düşük olduğu bulunmuştur. Bu konuda Türkiye'de yapılan bir çalışmada da (Altuğ-Özsoy ve Ardahan 2008) hemşirelerin \%78.5'inin uygulamaların kanita dayalı olmasın1, \%75.9'u kanıtların araştırmalardan elde edilmesi gerektiğini ve \%80.7'si KDU yararlı olduğunu ifade etmelerine rağmen uygulamada kullandıkları bilgi kaynaklarının daha çok araştırmaya dayanmayan kanıtlar (deneyimler, sezgiler, tartışmalar, gözlemler) olduğu belirlenmiştir. Ammouri ve ark. (2014) tarafindan yapılan bir çalışmada da benzer şekilde hemşirelerin KDU yönelik tutumlarının, bilgi/beceri ve uygulamalarından daha olumlu olduğu kanıtı elde edilmiştir. Hannes ve ark. (2007) "kanıta dayalı hemşirelik için engeller” üzerine yaptıkları bir odak grup çalışmasında, hemşirelerin KDU felsefesine inandığ 1 ancak günlük uygulamalarında; zaman eksikliği, bilgi, deneyim, yönetim destek eksikliği, kaynaklara ulaşmada (ör. bilgisayar veri bankası gibi) zorluk, hiyerarşik yapı, hemşirelik bakımı ile ilişkili araştırma eksikliği, KDU bakım öncelikleri ve KDU yürütmek için motivasyon, danışman eksikliği, uygulamayı değiştirmek için isteksizlik, kanıt üzerinde farmakolojik kampanyaların etkisi nedenleri ile rutin uygulamada kullanmadıkları kanıtlanmıştır. Aynı çalışmada hemşirelerin kanıta dayalı hemşirelik konusunda sorumluluklarını anlamada yetersiz oldukları, hasta bakımında "misafir" pozisyonunda bulundukları ve ortama uyum sağladıkları bulunmuştur.

Bu çalışmada hemşirelerin \%92.5'sinin KDU için eğitime gereksinimi olduğunu ifade ettikleri belirlendi. Bir çalışmada da (Melnyk, Fineout-Overholt, GallagherFord ve Kaplan 2012), hemşirelerin \%76.2'sinin KDU için daha fazla eğitime gereksinim duyduklarını ifade ettikleri belirlenmiştir. Bir başka çalışmada (Prior, Wilkinson ve Neville 2010) eğitimsel girişimler klinik alanda kanıtın kullanılmasını etkileyen, hemşirelerin uygun bilgi ve becerisini arttıran KDU'nın ayrılmaz en önemli faktörü olarak bulunmuştur. Hemşirelerin KDU'ya yönelik bilgi ve becerinin algılanması ve tutumları üzerine eğitim programlarının etkisinin değerlendirildiği yarı deneysel bir çalışmada (Sherriff ve ark. 2007) hemşirelerin eğitim öncesi KDU'nın önemine olan inançlarının yüksek olduğu ve eğitim sonrası bu inançlarının değişmediği, araştırma raporlarını değerlendirme ve uygulamaya yerleştirme algısının arttığı belirlenmiştir. Hemşirelerin KDU yönelik bilgi, tutum ve becerileri üzerine bilgisayar destekli eğitim programının etkisinin değerlendirildiği bir başka çalışmada (Hart, Eaton, Buckner ve Morrow 2008), hemşirelerin yayınlanmış araştırmaları alma, kanıtı değerlendirme ve uygulamaya dönüştürmesi ile ilişkili tutum, bilgi ve becerisinde artma olduğu kanıtlanmıştır. Girişim ve kontrol grubu kullanılarak yapılan bir çalışmada Saunders, Vehviläinen-Julkunen ve Stevens (2016) girişim grubuna KDU, kontrol grubuna ise yalnızca araştırmadan yararlanma ile ilişkili 4 saatlik eğitim verilmiş ve girişim sonrası birinci, sekizinci hafta ve dört ay sonra her iki grupta yer alan hemşirelerin KDU ile ilişkili bilgi ve öz etkililik düzeylerinin geliştiği belirlenmiştir.

Sunulan çalışmaya katılan hemşirelerin \%49.1'inin KDU'yı "bakımın araştırmalardan elde edilmiş bir temele dayandırılmasıdır" şeklinde tanımlamasına ve çoğunluğunun yaptıkları bakımın araştırma sonucuna dayalı olduğunu ifade etmelerine rağmen yalnızca \%4.04'nün hasta bakımında araştırma sonuçlarını kullandıklarını ifade etmeleri, sunulan çalışmada bireysel olarak hemşirelerin hasta bakımında araştırma kullanmadığ 1 , ancak kullanma isteklerinin olduğu, yaptığ uygulamaların araştırma temelli olduğuna inanmaları ve KDU'yı araştırma kullanımı olarak bildikleri şeklinde yorumlanabilir. KDU hemşirelikte bazı araştırmacılar tarafından klinik uygulamada araştırmanın optimal kullanımı olarak tanımlanmaktadır (Van Achterberg, Schoonhoven ve Grol 2008). Ancak, KDU için temel basamaklardan birisi araştırmalardan elde edilmiş mevcut bilginin rafine edilmesi, doğrulanması 
ve hasta bakımında kullanılması olmakla birlikte KDU yalnızca araştırmalardan elde edilmiş bilginin/kanıtın kullanımını içermemektedir. Ayrıca hemşirelikte hasta bakımında araştırma kanıtı kullanımının henüz emekleme aşamasında olduğu bildirilmektedir (Pravikoff ve ark. 2005). Bununla birlikte bilimsel bilgi olmadan KDU'dan söz edilemeyeceğinden dolayı öncelikle hemşirelere araştırma kanıtını kritik değerlendirme ve hasta bakımında kullanma yolunun öğretilmesi gerektiği söylenebilir.

Bu çalışmada hemşirelerin hasta bakımında kullandığı bilgi kaynağının eğitimleri sırasında aldıkları bilgi ile deneyimleri olduğu saptandı. Çalışmadan elde edilen bu sonuç hemşirelerin araştırma ve KDU konusunda bilgilerinin yeterli olmadığını, bu nedenle eğitimleri sırasında aldıkları bilgi ve deneyimlerine güvendiklerini göstermektedir. Norveç’te yapılan bir çalışmada da (Berland ve ark. 2012) birçok hemşirenin araştırmalardan elde edilmiş kanıtı kullanmadığ1, bunun yerine kendisi ya da arkadaşının bilgisini, eğitimi sırasında kazandığı bilgiyi, hemşirelik literatürü ve kişisel uzman bilgisini kullandıkları saptanmıştır. Bir başka çalışmada (Fairbrother, Cashin, Conway, Symes ve Graham 2016) hemşire ve ebelerin kullandıkları ilk sıradaki bilgi kaynağının deneyimler olduğu, araştırma temelli bilgiyi son sıralarda kullandıkları, \%28.7'sinin uygulamayı değiştirmek için araştırma kullanımında kendilerini yeterli görmedikleri bulunmuştur. KDU yararlarına ve uygulamayı geliştirmek için tasarlanmış araştırma ve araştırmaların yayınlandığ1 dergi sayısı ve buna bağlı olarak ulaşılabilir kanıt sayısında artış olmasına rağmen bu konuda yapılmış önceki araştırma kanıtları, sunulan çalışmada hemşirelerin hasta bakımında kullandıkları bilgi kaynaklarına benzer şekilde, hemşirelerin rutin klinik uygulamalarında araştırmalardan elde edilmiş bilimsel bilgiyi kullanmak yerine arkadaşlarını (Thiel ve Ghosh 2008), hekimleri (Mills, Field ve Cant 2009) bilgi kaynağı olarak kullanmayı tercih ettikleri ve birçoğunun eğitimleri sırasında aldıkları bilgiye, deneyimlerine güvendikleri (Altuğ-Özsoy ve Ardahan 2008; Bringsvor, Bentsen ve Berland 2014; Egerod ve
Hansen 2005; Gerrish ve ark. 2008; Perez-Campos, Sanchez-Garcia ve Pancorbo-Hidalgo 2014; Pravikoff ve ark. 2005) ve hemşirelerin KDU için gereken araştırma bilgi, beceri ve anlama konusunda yeterli bilgiye sahip olmadıkları (Maaskant, Knops, Ubbink ve Vermeulen 2013; Melnyk ve Fineout-Overholt 2005; Wang, Jiang, Wang, Wang ve Bai 2013) yeni fikirleri yaşama geçirmek için zamanları (Ammouri ve ark. 2014; Kocaman ve ark. 2010; Koehn ve Lehman 2008; Majid ve ark. 2011; Tan, Akgün-Şahin ve Kardaş-Özdemir 2012) ve bilgilerinin olmadı̆̆ 1 (Koehn ve Lehman 2008; Majid ve ark. 2011), uygulama için bilgiye ulaşmada zaman eksikliği (Maaskant, Knops, Ubbink ve Vermeulen 2013; Mills ve ark. 2009) araştırma farkındalığı, araştırmanın kalitesini değerlendirmede teknik beceri (Gerrish ve Clayton 2004) ve uygun bilgiyi nasıl alacakları konusunda bilgi ve beceri eksikliği (Pravikoff ve ark. 2005) nedeni ile rutin hemşirelik uygulamasında bilimsel kanıt kullanmanın başarılı olmadığı belirlenmiştir. Bir başka çalışmada da benzer şekilde hemşirelerin çoğunluğunun kendi bilgisi, arkadaşlarının bilgisi, uzman personel, hemşirelik literatürü ve hemşirelik eğitimi sırasında kazandıkları bilgiyi kullandıkları ancak nadiren araştırma kanıtı kullandıkları belirlenmiştir (Berdland ve ark. 2012). Son yıllarda yapılan bir çalışmada (Farokhzadian, Khajouei ve Ahmadian 2015) hemşirelerin elektronik kaynaklar yerine yayınlanmış dergi ve arkadaş, hekim gibi kaynakları daha fazla kullandıkları ve güncel bilgi kaynaklarını kullanmada belirgin eksiklik olduğu, bilgiyi arama ve becerilerini geliştirme konusunda yetersiz oldukları kanıtlanmış (Pravikoff ve ark. 2005), hemşirelerin doğru klinik sorular sormak için bilgi ve beceri, kanıtı araştırma, kanıtı değerlendirme ve uygulama içine entegre etme (Estabrooks 1998; Haynes ve Haines 1998; Pravikoff ve ark. 2005); bilgisayar kullanma ve istatistiksel bilgiyi yorumlama gibi bireysel engeller olduğu belirlenmiştir (Thompson, McCaughan, Cullum, Sheldon ve Raynor 2005). Bazı çalışmalarda klinik uygulamada araştırma kullanan birkaç hemşire bulunduğu (Adib-Hajbaghery 2009; Bonner ve Sando 2008), master ve doktora derecesi almış klinik hemşire uz- 
manların klinik karar vermede kanıtın primer kaynağ olarak araştırma literatürünü kullandığ 1 bulunmuştur (Profetto-McGrath, Bulmer-Smith, Hugo, Taylor ve El-Hajj 2007).

$\mathrm{Bu}$ çalışmada hemşirelerin çoğunluğu tarafindan eleman, zaman, fizik ortam, malzeme yetersizliğinin KDU için engeller olduğunu ifade ettikleri saptandı. Yapılan bir çalışmada da (Ammouri ve ark. 2014) bizim çalışmamıza paralel şekilde zaman ve kaynak yetersizliğinin KDU için en önemli engel olduğu belirlenmiştir. Hemşirelerin KDU ile ilişkili bilgi, tutum ve becerilerini belirlemek üzere yapılmış diğer çalışmalarda da (Fink, Thompson ve Bonners 2005; Pravikoff ve ark. 2005; Williamson ve ark. 2015) hemşirelerin literatür taraması, uygulamada araştırma kanıtını kullanmak ve araştırma aktivitelerine katılmak için zaman kısıtllılığ ve iş yükü KDU için en önemli engeller olarak bulunmuştur. Bir başka çalışmada da (Brown ve ark. 2009) KDU için hemşirenin zaman ve otonomi eksikliği en önemli engel olarak belirlenmiştir. Hemşirelerin araştırma kullanımını kolaylaştıran ve engelleyen faktörleri belirlemek üzere yapılan bir literatür incelememesinde (Heydari ve Zeydi 2014) hemşirelerin araştırma kullanımı için en önemli engelin organizasyon ile ilişkili faktörler olduğu saptanmıştır. Araştırma kullanımı ile ilişkili en önemli kolaylaştırıcılar ise; hemşirelerin araştırmayı kritik değerlendirme bilgi ve becerilerini arttıracak eğitim, bilgili meslektaş ve hemşirelik fakültesinden destek, klinik değerlendirme için bir uzman komitesine ulaşabilme, makale araştırabilmek için İngilizce dil becerisi, araştırmayı yürütmek ve internet gibi kolaylıklara erişebilmek için yeterli kaynaklar olarak belirlenmiștir.

$\mathrm{Bu}$ çalışmada hemşirelerin \%97'si KDU için kurumsal desteğin önemli olduğunu ve \%54.4'ünün çalıştığı kurumu KDU için yeterli gördüğü ve "yönetimin değişim ve yeniliğe açık ve destekleyici olması" önerisinde bulundukları belirlendi. Araştırma kanıtları kurumsal ve liderlik desteğinde yetersizlik, zaman kısıtlılığ ve kaynak eksikliğinin KDU'nın engelleri olduğunu göstermektedir (Mcsherry, Artley ve Holloran 2006;
Melynk ve Fineout-Overholt 2004). Bir çalışmada (Rycroft-Malone ve ark. 2004) organizasyon deste$\breve{g} \mathrm{i}$, uygun güncel araştırmaların, iş birlikçi ve liderlik yaklaşımının olmaması, kaynaklara sınırlı ulaşma gibi faktörlerin uygulamada bilgi kullanım engelleri olduğu belirlenmiştir. Hemşirelerin KDU destekleyen bir kurum kültürüne gereksinimi vardır. Çünkü kurum kültürü KDU destekleyebilir ya da engelleyebilir. Bir çalışmada (Melynk, Fineout-Overholt, Giggleman ve Cruz 2010) hemşirelerin KDU inançları ile örgüt kültürü arasında önemli derecede ilişki olduğu bulunmuştur. Bu nedenle hemşireleri KDU ve araştırma kullanı$\mathrm{m}$ konusunda teşvik etmek için klinik alanda öğretici ve destekleyici profesyonel bir çevreye uygun örgütsel altyapı ve KDU yönelik kültürün oluşturulmasının gerekli olduğu söylenebilir.

$\mathrm{Bu}$ çalışmada hemşirelerin çoğunluğu yaptıkları bakımin hasta üzerindeki etkisini bildiğini, KDU yapabilecekleri konusunda kendilerine güvendiklerini, konu ile ilişkili eğitime gereksinimleri olduğunu ifade ettikleri saptandı. Ayrıca KDU için eleman, zaman, klinik ortam ve malzeme yetersizliği, hekim istemlerine yönelik ve iş merkezli çalışma ve araştırma sonuçlarına ulaşamama gibi bireysel faktörler nedenleri ile KDU yönelik çalışamadıklarını ifade ettikleri belirlendi. İngiltere'de iki hastanede çalışan deneyimli ve genç hemşireler ile yapılan bir çalışmada (Gerrish ve ark. 2008) tüm hemşirelerin uygulama için kanıta erişim ve kanitı kullanmada kendilerine güvendikleri, genç hemşirelerin kaynak ve zaman eksikliğini en büyük engel olarak gördükleri belirlenmiştir. KDU başarmayı etkileyen faktörleri değerlendirmenin kompleks olduğu bildirilmektedir Klinik alanda hemşirelerin KDU becerisini geliştirme ve klinik alanda en iyi kanıtı kullanmanın etkisine inanması ile en iyi klinik kararların verilmesinin başarılabileceği ileri sürülmektedir (Melnyk ve ark. 2014). Bu bilgiye göre bu çalışmaya katılan hemşirelerin KDU olumlu bakmaları, KDU yapabilecekleri konusunda kendilerine güvenmeleri gereksinimleri olan eğitim, kurumsal destek ile hasta bakımı için en iyi kararların verilmesi sağlanabilir şeklinde yorumlanabilir. 


\section{SONUÇ VE ÖNERİLER}

Sunulan çalışmada hemşirelerin KDU tanımları ve hasta bakımında çoğunlukla lisans eğitimleri sırasında aldıkları bilgiyi kullanmaları, yarısına yakının araştırma sonuçlarına ulaşamaması ve KDU ile ilişkili eğitim isteklerine göre KDU ile ilişkili bilgilerinin yeterli olmadığı sonucuna varıldı. Günümüzün karmaşık sağlık sistemlerinde, hiçbir sağlı mesleğinin tek başına sağlığa katkıda bulunabilecek bilgi ve beceriye sahip olmadığı ve Türkiye'de her eğitim düzeyine hemşire ünvanı verilmesi, aynı görev ve sorumlulukların bekleniyor olması önemli bir sorun olmakla birlikte hemşire liderlerin ve lisansüstü eğitim almış hemşirelerin önderliğinde hemşirelerin kanıt temelli çalışmaları hasta bakım kalitesini arttırmaya katkı verebilir. $\mathrm{Bu}$ bağlamda KDU için destekleyici bir kültür oluşturmak, hemşirelik uygulamalarının kanıta dayalı olması için hemşirelere gereksinim duyduğu zaman, eğitim toplantıları ve kaynaklar temin edilerek KDU önündeki engellerin azaltılması, optimal hasta sonuçları için en iyi kanıtın elde edilmesi ve kanitın uygulanabileceği klinik ortamların tasarlanması ve desteklenmesinde kilit noktada bulunan liderler, akademisyenler, kurum yöneticilerinin işbirliğini içeren interdisipliner ekip çalışması ve KDU modellerin kullanılmasının yararlı olabileceği söylenebilir.

\section{KAYNAKLAR}

Adib-Hajbaghery, M. (2009). Evidence-based practice: Iranian nurses' perceptions. Worldviews Evid Based Nurs. 6(2): 93-101.

Altuğ-Özsoy, S., Ardahan, M. (2008). Research on knowledge sources used in nursing practices. Nurse Educ Today, 28(5): 602-609.

Ammouri, A. A. ve ark. (2014). Evidenced-based practice: Knowledge, attitudes, practice and perceived barriers among nurses in Oman. Sultan Qaboos Univ Med J, 14(4): e537-e545.

Beckette, M. ve ark. (2011). Bridging the gap between basic science and clinical practice: The role of organizations in addressing clinician barriers. Implement Sci, 6: 34 .

Berland, A., Gundersen, D., Bentsen, S. B. (2012). Evidence-based practice in primary cared an explorative study of nurse practitioners in Norway. Nurse Education in Practice, 12(6): 361-365.

Beyea, S. C., Slattery, M. J. (2013). Historical perspectives on evidence-based nursing. Nurs Sci Q, 26(2): 152-155.
Bonner, A., Sando, J. (2008). Examining the knowledge, attitude and use of research by nurses. J Nurs Manag, 16(3): 334-343.

Bringsvor, H. B., Bentsen, S. B., Berland, A. (2014). Sources of knowledge used by intensive care nurses in Norway: An exploratory study. Intensive Crit Care Nurs, 30(3): 159-166.

Brown, C. E., Wickline, M. A., Ecoff, L., Glaser, D. (2009). Nursing practice, knowledge, attitudes and perceived barriers to evidence-based practice at an academic medical center. $J$ Adv Nurs, 65(2): 371-381.

Chien, W. T., Bai, Q., Wong, W. K., Wang, H., Lu, X. (2013). Nurses' perceived barriers to and facilitators of research utilization in Mainland China: A cross-sectional survey. The Open Nursing Journal, 12(7): 96-106.

Egerod, I., Hansen, G. M. (2005). Evidence-based practice among Danish cardiac nurses: A national survey. $J$ Adv Nurs, 51(5): 465473.

Estabrooks, C. A., Floyd, J. A., Scott-Findlay, S., O’Leary, K. A., Gushta, M. (2003). Individual determinants of research utilization: A systematic review. J Adv Nurs, 43(5): 506-520.

Estabrooks, C. A., Chong, H., Brigidear, K., Profetto-McGrath, J. (2005). Profiling Canadian nurses' preferred knowledge sources for clinical practice. Can J Nurs Res, 37(2): 118-140.

Fairbrother, G., Cashin, A., Conway, R., Symes, A., Graham, I. (2016). Evidence based nursing and midwifery practice in a regional Australian health care setting: Behaviours, skills and barriers. Collegian, 23(1): 29-37.

Farokhzadian, J., Khajouei, R., Ahmadian, L. (2015). Information seeking and retrieval skills of nurses: Nurses readiness for evidence based practice in hospitals of a medical university in Iran. International Journal of Medical Informatics, 84(8): 570-577.

Fink, R., Thompson, C. J., Bonners, D. (2005). Overcoming barriers and promoting the use of research in practice. The Journal of Nursing Administration, 35(3): 121-129.

Gerrish, K., Ashworth, P., Lacey, A., Bailey, J. (2008) Developing evidence-based practice: Experiences of senior and junior clinical nurses. $J A d v$ Nurs, 62(1): 62-73.

Gerrish, K., Clayton, J. (2004). Promoting evidence-based practice: An organizational approach. J Nurs Manag, 12(2): 114-123.

Hannes, K. ve ark. (2007). Barriers to evidence-based nursing: A focus group study. J Adv Nurs. 60(2): 162-167.

Hart, P., Eaton, L., Buckner, M., Morrow, B. N. (2008). Effectiveness of a computer-based educational program on nurses' knowledge, attitude, and skill level related to evidence-based practice, Worldviews on Evidence-Based Nursing, 5(2): 75-84. 
Haynes, B., Haines, A. (1998). Barriers and bridges to evidence based clinical practice. BMJ, 317(7153): 273-276.

Heater, B., Becker, A., Olson, R. (1988). Nursing interventions and patient outcomes: A meta-analysis of studies. Nursing Research, 37: 303-307.

Heydari, A., Zeydi, A. E. (2014). Barriers to and facilitators of research utilization among Iranian nurses: A literature review. J Caring Sci, 3(4): 265-275.

Kocaman, G. ve ark. (2010). Barriers to research utilization by staff nurses in a university hospital, J Clin Nurs, 19(13-14): 1908-1918.

Koehn, M. L., Lehman, K. (2008). Nurses' perceptions of evidencebased nursing practice. $J$ Adv Nurs, 62(2): 209-215.

Maaskant, J. M., Knops, A. M., Ubbink, D. T., Vermeulen, H. (2013). Evidence-based practice: A survey among sediatric nurses and pediatricians. Journal of Pediatric Nursing, 28(2): 150-157.

Majid, S. ve ark. (2011). Adopting evidence based practice in clinical decision making: Nurses' perceptions, knowledge, and barriers. J Med Libr Assoc, 99(3): 229-236.

McCaughan, D., Thompson, C., Cullum, N., Sheldon, T. A., Thompson, D. R. (2002). Acute care nurses' perceptions of barriers to using research information in clinical decisionmaking. $J A d v$ Nurs, 39(1): 46-60.

McSherry, R., Artley, A., Holloran, J. (2006). Research awareness: An important factor for evidence-based practice? Worldviews Evid Based Nurs, 3(3): 103-115.

Melnyk, B. M., Fineout-Overholt, E., Gallagher-Ford, L., Kaplan, L. (2012). The state of evidence-based practice in US Nurses. JONA, 42(9): 410-417.

Melnyk, B. M., Fineout-Overholt, E., Gallagher-Ford, L., StillWell, S. B. (2011). Evidence-based practice, step by step: Sustaining evidence-based practice through organizational policies and an innovative model. Am J Nurs, 111(9): 57-60.

Melnyk, B. M., Fineout-Overholt, E., Giggleman, M., Cruz, R. (2010). Correlates among cognitive beliefs, EBP implementation, organizational culture, cohesion and job satisfaction in evidence based practice mentors from a community hospital system. Nursing Outlook, 58(6): 301-308.

Melnyk, B. M., Gallagher-Ford, L., Long, L. E., Fineout-Overholt, E. (2014). The establishment of evidence-based practice competencies for practicing registered nurses and advanced practice nurses in the real-world clinical settings: Proficiencies to improve healthcare quality, reliability, patient outcomes, and costs. Worldviews on Evidence-Based Nursing, 11(1): 5-15.
Melnyk, B. M., Fineout-Overholt, E. (2005). Rapid critical appraisal of randomized controlled trials (RCTs): An essential skill for evidence-based practice (EBP). Pediatr Nurs, 31(1): 50-52.

Melnyk, B. M. ve ark. (2004). Nurses' perceived knowledge, beliefs, skills, and needs regarding evidence-based practice: Implication for accelerating the paradigm shift. Worldviews Evidence-Based Nursing, 1(3): 185-193.

Mills, J., Field, J., Cant, R. (2009). The place of knowledge and evidence in the context of Australian general practice nursing? Worldviews on Evidence-Based Nursing, 6(4): 219-228.

Perez-Campos, M. A., Sanchez-Garcia, I., Pancorbo-Hidalgo, P. L. (2014). Knowledge, attitude and use of evidence-based practice among nurses active on the internet. Invest Educ Enferm, 32(3): 451-460.

Pravikoff, D., Tanner, A., Pierce, S. (2005). Readiness of US nurses for evidence-based practice. American Journal of Nursing, 105(9): $40-51$

Prior, P., Wilkinson, J., Neville, S. (2010). Practice nurse use of evidence in clinical practice: A descriptive survey. Nurs Prax $N Z$, 26(2): 14-25.

Profetto-McGrath, J., Bulmer Smith, K., Hugo, K., Taylor, M., ElHajj, H. (2007). Clinical nurse specialists' use of evidence in practice: A pilot study. Worldviews on Evidence-Based Nursing, 4(2): 89-96.

Rycroft-Malone, J. ve ark. (2004). An exploration of the factors that influence the implementation of evidence into practice. Journal of Clinical Nursing, 13(8): 913-924.

Sackett, D., Rosenberg, W., Gray, J., Haynes, R., Richardson, W. (1996). Evidence based medicine: What it is and what it isn't. British Medical Journal, 312(7023): 71-72.

Saunders, H., Vehviläinen-Julkunen, K., Stevens, K. R. (2016). Effectiveness of an education intervention to strengthen nurses'readiness for evidence-based practice: A single-blind randomized controlled study. Applied Nursing Research, 31(11): 175185 .

Sherriff, K. L., Wallis, M., Chaboyer, W. (2007). Nurses' attitudes to and perceptions of knowledge and skills regarding evidencebased practice. International Journal of Nursing Practice, 13(6): 363-369.

Tan, M., Akgün-Şahin, Z., Kardaş-Özdemir, F. (2012). Barriers of research utilization from perspective of nurses in Eastern Turkey. Nursing Outlook, 60(1): 44-50.

Thiel, L., Ghosh, Y. (2008). Determining registered nurses' readiness, for evidence-based practice. Worldviews on Evidence-Based Nurs., 5(4): 182-192. 
Thompson, C., McCaughan, D., Cullum, N., Sheldon, T., Raynor, P. (2005). Barriers to evidence-based practice in primary care nursing-why viewing decision-making as context is helpful. $J$ Adv Nurs., 52(4): 432-444.

Van-Achterberg, T., Schoonhoven, L., Grol, R. (2008). Nursing implementation science: How evidence-based nursing requires evidence-based implementation. Journal of Nursing Scholarship, 40(4): 302-310.

Wang, L. P., Jiang, X. L., Wang, L., Wang, G. R., Bai, Y. J. (2013). Barriers to and facilitators of research utilization: A survey of registered nurses in China. PLOS ONE, 8(11): 1-9.
Williamson, K. M., Almaskari, M., Lester, Z., Maguire, D. (2015). Utilization of evidence-based practice knowledge, attitude, and skill of clinical nurses in the planning of professional development programming. J Nurses Prof Dev, 31(2): 73-80.

Yılmaz, M. (2005). Hemşirelik bakım hizmetinin kalitesini geliştirme yolu olarak kanıta dayalı uygulama. C.Ü. Hemşirelik Yüksekokulu Dergisi, 9 (1): 41-48. 
